\title{
NUEVA COMBINACIÓN PARA UNA ESPECIE DEL GÉNERO SERJANIA (SAPINDACEAE-PAULLINIEAE) ENDÉMICA EN MÉXICO
}

\author{
María S. Ferrucci ${ }^{1,3}$ y Rosalinda Medina-Lemos ${ }^{2}$ \\ ${ }^{1}$ Consejo Nacional de Investigaciones Científicas y Técnicas-Universidad Nacional \\ del Nordeste, Instituto de Botánica del Nordeste, C.C. 209, 3400 \\ Corrientes, Argentina. \\ ${ }^{2}$ Universidad Nacional Autónoma de México, Instituto de Biología, 04510 \\ México, Distrito Federal, México. \\ ${ }^{3}$ Autor para la correspondencia: msferrucci@yahoo.com.ar
}

\section{RESUMEN}

Se documenta la nueva combinación Serjania pygmaea (Radlk.) Ferrucci \& Medina (Sapindaceae-Paullinieae), basada en Cardiospermum pygmaeum Radlk., taxon descrito con base en un ejemplar florífero procedente de Puebla, México. Se presenta una descripción completa y una ilustración de la especie. Finalmente, Serjania pygmaea es comparada con las especies mexicanas de Serjania más similares.

Palabras clave: México, nueva combinación, Sapindaceae, Serjania.

\begin{abstract}
The new combination Serjania pygmaea (Radlk.) Ferrucci \& Medina (SapindaceaePaullinieae), based on Cardiospermum pygmaeum Radlk., is here provided. Cardiospermum pygmaeum was known only from the type, a flowering collection from Puebla, Mexico. We present a full description and an illustration of the species. Finally, Serjania pygmaea is compared to the morphologically similar Mexican species of Serjania.
\end{abstract}

Key words: Mexico, new combination, Sapindaceae, Serjania.

La posibilidad de estudiar las colecciones de Sapindaceae, depositadas en los herbarios mexicanos MEXU y ENCB, permitió analizar material con frutos casi 
maduros de Cardiospermum pygmaeum Radlk., descrita en 1921 con base en un ejemplar que solamente presenta flores, recolectado por C. A. Purpus en el estado de Puebla, hace más de cien años. Durante la revisión del género, Ferrucci (2000) sólo tuvo acceso al estudio de tres ejemplares de esta planta, todos ellos con flores, pero carentes de frutos. Si bien el material correspondía a la tribu Paullinieae, subtribu Paulliniinae (Radlkofer, 1931-1932), la asignación de género no era confiable, ya que para ello se requiere conocer el tipo de fruto. En el 2011 se realizaron varias exploraciones para obtener colecciones fértiles de esta especie, especialmente con fruto maduro para poder completar su descripción y designación genérica. En el 2012 fue posible recolectar varios ejemplares con frutos, permitiendo observar que en la madurez éstos se separan en 3 mericarpos, con la porción seminífera en el ápice y el ala basal. Esta observación nos lleva a proponer la nueva combinación Serjania pygmaea, registrando hasta el momento 51 especies para el género en México.

Serjania Mill. es uno de los géneros americanos más numerosos de la familia, con ca. 230 especies. El principal centro de diversidad se encuentra en Brasil (Ferrucci y Acevedo-Rodríguez, 2005; Ferrucci, 2008; Somner et al., 2010), siguiéndole en orden de importancia Bolivia con ca. 58 especies y México.

Serjania comparte la subtribu Paulliniinae con Balsas J. Jiménez Ram. \& K. Vega, Cardiospermum L., Houssayanthus Hunz., Lophostigma Radlk., Paullinia L. y Urvillea Kunth (Radlkofer, 1931-1932). Se distingue de los géneros relacionados por los frutos esquizocárpicos con mericarpos con la porción seminífera en la porción distal y el ala proximal, a excepción de Lophostigma con quien comparte los caracteres del fruto, pero se diferencia por la morfología polínica y el número cromosómico. En Paullinieae se reconocen cuatro tipos de polen (Ferrucci \& Anzótegui, 1993). Serjania comparte el polen heteropolar, hemitrisincolporado, peroblado u oblado con Balsas, Cardiospermum, Houssayanthus y Urvillea.

\section{MATERIALES Y MÉTODOS}

Este estudio está basado en la literatura publicada, en el análisis de ejemplares de herbario y en la recolección de material botánico por los autores durante el trabajo de campo realizado en 2011 y 2012. Se consultaron también especímenes depositados en los herbarios ENCB, F, GH, L, MEXU, NY y US.

Para la obtención de las muestras foliares se trabajó con material conservado en FAA (formol - alcohol $70^{\circ}$ - ácido acético), el cual previo a la metalización fue sometido a una serie creciente de acetona y secado en punto crítico con $\mathrm{CO}_{2}$. 
Los granos de polen fueron obtenidos de anteras de especímenes de herbario. Las muestras para microscopio óptico fueron acetolizadas de acuerdo con la técnica de Erdtman (1966) y montadas en gelatina glicerinada. Los preparados permanentes se encuentran depositados en la palinoteca del Instituto de Botánica del Nordeste, Universidad Nacional del Nordeste (PAL-CTES). Las medidas del eje polar y del diámetro ecuatorial fueron obtenidas a partir de 20 mediciones usando un microscopio Leica DM LB2. La terminología usada para describir los granos de polen es la propuesta por Erdtman (1966) y por Punt et al. (2007).

Las fotomicrografías, de caras adaxial y abaxial de hoja, y de granos de polen acetolizados, se obtuvieron con un microscopio electrónico de barrido Jeol $5800 \mathrm{LV}$ a $10 \mathrm{kV}$. La metalización se llevó a cabo con un baño de oro-paladio.

\section{RESULTADOS}

Serjania pygmaea (Radlk.) Ferrucci \& Medina, comb. nov. (Figs. 1-3).

= Cardiospermum pygmaeum Radlk., Feddes Repert. Spec. Nov. Regni Veg. 17: 361. 1921. "In Mexico: C. A. Purpus, no. 2616! (Puebla, Cerro de Santa Lucia, rocky soil, alt. 8-9000 ped., m. Jul. 1907, fl.; Hb. Ber.)”. TIPO: MÉXICO. Puebla: cerro de Santa Lucía, Jul 1907, C. A. Purpus 2616 (holotipo: B, destruido; isotipo: L!).

Sufrútice trepador de poco más de $1 \mathrm{~m}$ de alto o a veces erecto de ca. $30 \mathrm{~cm}$; monoico con flores estaminadas y hermafroditas funcionalmente pistiladas. Indumento de pelos simples, curvos o crespos y pelos glandulares curvos dispersos en tallos, pecíolo y ejes de la inflorescencia. Tallos castaño-rojizos, 6-costados, luego subteretes, pubescentes, 1 a $1.6 \mathrm{~mm}$ de diámetro, en la base leñosos, teretes, 2 a 2.5 $\mathrm{mm}$ de diámetro; cámbium único. Hojas 3 -folioladas; estípulas subuladas, caducas, 1.5 a $2.5 \mathrm{~mm}$ de largo, 0.5 a $0.7 \mathrm{~mm}$ de ancho, pilosas; pecíolo canaliculado o bicanaliculado, 1.8 a $5.2 \mathrm{~cm}$ de largo; peciólulo angostamente alado en el folíolo terminal, 4.5 a $21 \mathrm{~mm}$ de largo, folíolos laterales subsésiles o con peciólulo ca. $4 \mathrm{~mm}$ de largo; folíolos cartáceos, discoloros, hipostomáticos, el folíolo terminal ovado, ovado-romboidal u obovado-romboidal, los laterales ovados u ovado-anchos, 1.9 a $7 \mathrm{~cm}$ largo, 1.1 a $4.4 \mathrm{~cm}$ ancho, asimétricos con la semilámina externa más ancha; base decurrente en el folíolo terminal, redondeado-decurrente, obtuso-decurrente o truncada en los laterales; ápice obtuso o agudo, mucronado; margen inciso-den- 


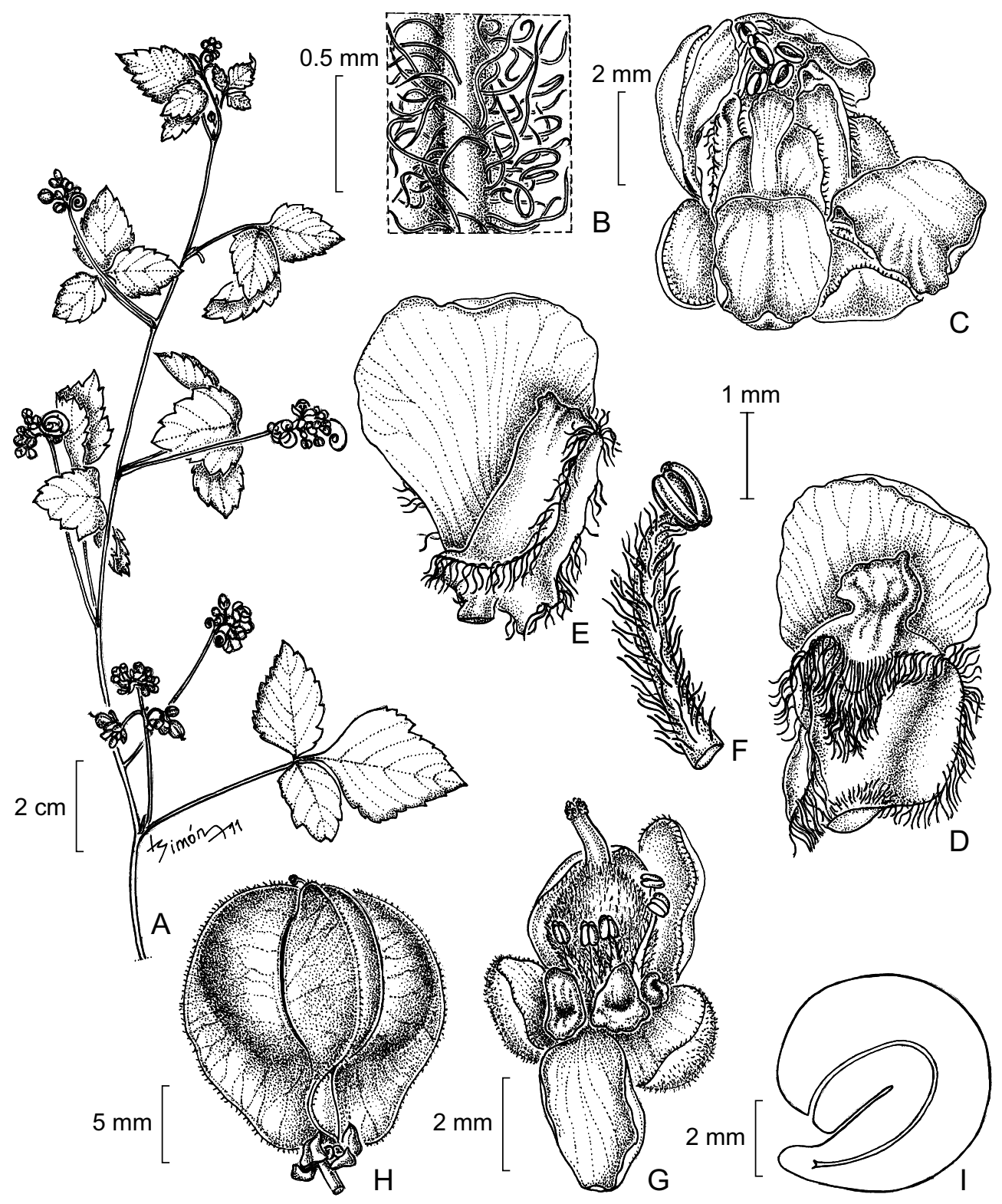

Fig. 1. Serjania pygmaea. A. rama; B. detalle de cara abaxial de hoja; C. flor estaminada; D. pétalo posterior, cara interna; E. pétalo anterior, cara interna; F. estambre de flor estaminada; G. flor pistilada desprovista de pétalos, mostrando los lobos nectaríferos posteriores y uno de los anteriores; H. fruto; I. embrión (A-B: Purpus $2616 a$ F; C-G: Purpus $2616 a$ GH; H-I: A. Salinas \& E. Martinez-Correa 7893 MEXU). 

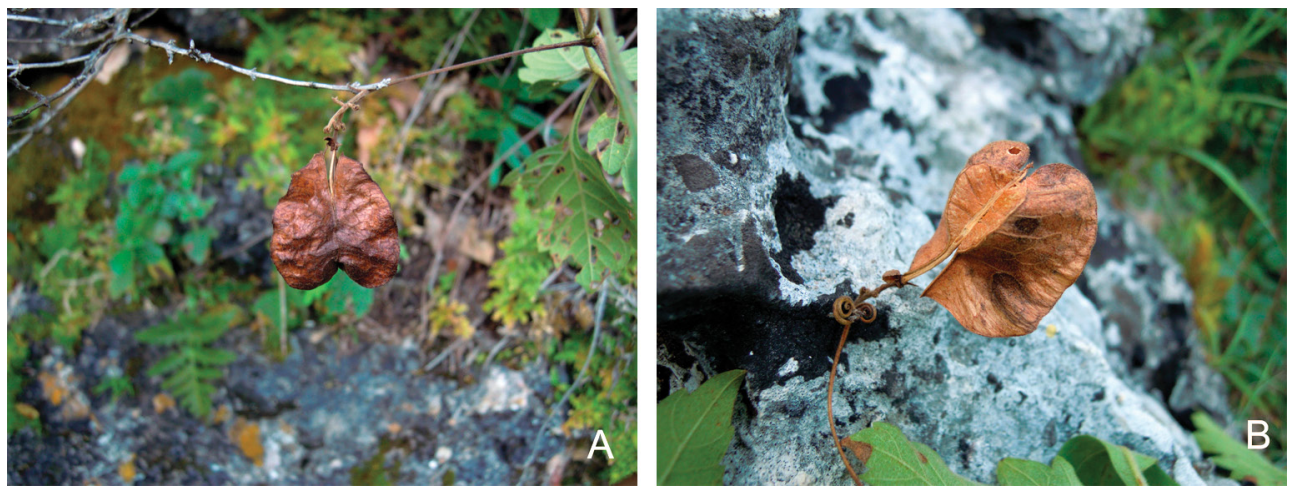

Fig. 2. Serjania pygmaea. A. fruto maduro con sus tres mericarpos; B, fruto del cual se ha desprendido un mericarpo, se aprecian las paredes septales (Ferrucci et al. 3109 CTES, MEXU)

tado, 2-4-incisiones, 6-16 dientes obtusos, por lo común glandulares; cara adaxial pilosa con pelos rectos y subadpresos, cara abaxial pubescente, pelos blanquecinos sedosos, subadpresos y curvos, venación craspedódroma, venas notables en el envés. Inflorescencia con ejes castaño-rojizos, pubescentes, pedúnculo cuadrangular, de 2.4 a $7 \mathrm{~cm}$ de largo, con 2 zarcillos gráciles en la base del raquis, éste ca. 1 $\mathrm{cm}$ de largo, 1 a 9 cincinos en verticilos o alternos, cincinos con 3 o 4 flores, con pedúnculo (0.5)1.5 a $5.5 \mathrm{~mm}$ largo, pedicelo 3 a $4 \mathrm{~mm}$ de largo, articulado en la base o hasta $1 / 2$ basal; brácteas triangular-subuladas, pubescentes, 0.7 a $2 \mathrm{~mm}$ de largo, bractéolas más pequeñas. Sépalos 5 , libres, 2 externos ovado-suborbiculares, cuculados, 2.5 a $3 \mathrm{~mm}$ de largo, 2.5 a $3 \mathrm{~mm}$ de ancho, pubescentes, 3 internos obovados, 3 a $4 \mathrm{~mm}$ de largo, 1.7 a $3 \mathrm{~mm}$ de ancho, tomentosos, pelos diminutos crespos; pétalos obovados, unguiculados, ca. $4.3 \mathrm{~mm}$ de largo, 2.5 a $3 \mathrm{~mm}$ de ancho, densamente glandulosos en la cara interna, escama de los pétalos posteriores de 3 a $3.5 \mathrm{~mm}$ de largo, con la cresta erosa, apéndice deflexo breve, con mechón de pelos; lobos nectaríferos 4 , los 2 posteriores ovoide-obtusos, 1.5 a $1.7 \mathrm{~mm}$ de alto, los anteriores más pequeños, de contorno suborbicular; glabros; androginóforo o andróforo glabros; flores estaminadas con estambres 3.3 a $3.7 \mathrm{~mm}$ de largo, filamentos acintados, pubescentes, anteras subglabras, pistilodio pubérulo; flores pistiladas con estambres 1.6 a $2 \mathrm{~mm}$ de largo, gineceo de ca. $4.4 \mathrm{~mm}$ de largo, ovario obovoide, velloso, estilo 0.4 a $0.7 \mathrm{~mm}$ de largo, ramas del estigma de igual longitud. Frutos de contorno obovado, cartáceos, el ápice emarginado, 22 a $25 \mathrm{~mm}$ de largo, a la altura de la porción seminífera 18 a $24 \mathrm{~mm}$ de ancho, lóculos hinchados con venación inconspicua, castaño-amarillentos, con cresta dorsal, 3 a $5 \mathrm{~mm}$ de ancho, 
alas ca. $9 \mathrm{~mm}$ de largo, poco más claras que la porción seminífera, sin constricción debajo del lóculo; pared septal subcartácea ca. $10 \mathrm{~mm}$ de ancho; epicarpo piloso, pelos breves y curvos, endocarpo glabro. Semillas subesféricas, 6.2 a $7.5 \mathrm{~mm}$ de largo, 6.5 a $7 \mathrm{~mm}$ de ancho, insertas poco por arriba de la base de lóculo; embrión con el cotiledón externo curvo y el interno biplicado.

Granos de polen (Fig. 3 D-F) heteropolares, hemitrisincolporados, oblados o peroblados; media de eje polar 19.6, rango (16.4-24.9) $\mu \mathrm{m}$; media de diámetro ecuatorial 40.9, rango (33.4-48.5) $\mu \mathrm{m}$; exina tectada, cara proximal perforado-rugulada y cara distal perforado-psilada, colpos lineares.

Distribución, ecología y fenología. Planta endémica de los estados de Guerrero, Puebla y Oaxaca, México (Fig. 4); habita en matorrales xerófilos, bosques tropicales caducifolios y bosques de encino, entre los 1450-2150 m s.n.m.; florece de julio a septiembre, con frutos maduros en septiembre-octubre.

Material examinado: México. Guerrero: municipio Iguala de la Independencia, Limestone hill ca. 9 miles north of Iguala, elev. 1450-1700 m, access road to antenna, road leaving Mex. Hwy 95 D near km 155, 26.VII.1968 (fl), W. R. Anderson \& C. Anderson 4897 (ENCB); municipio Iguala de la Independencia, $3.5 \mathrm{~km}$ de la entrada a la torre microondas Tuxpan, 18²3'37,1" N, 99²8'44,2" W, 6.X.2012 (fr), M. S. Ferrucci, R. Medina-Lemos, E. Martínez-Salas y R. Redonda-Martínez 3109 (CTES, MEXU). Oaxaca: distrito Nochixtlán, El Parián, 28.VII.1907 (fl), C. Conzatti 1923 (F) pro parte; distrito Centro, Monte Albán, 14.X.1932 (fl), C. Conzatti 4793 (MEXU); Valley of Oaxaca, 8.09.1894 (fl), E. W. Nelson 1237 (GH); distrito Teotitlán, $5 \mathrm{~km}$ al S de Tecomavaca y $23 \mathrm{~km}$ al W, rumbo a Santa María Ixcatlán, 17050' N, 9707' W, 16.IX.1991 (fl), A. Salinas \& E. Martínez-Correa 6146 (MEXU); municipio Villa Tepelmeme de Morelos, distrito Coixtlahuaca, cerro Paraje Ladrón, 17.IX.1994 (fr), 1807' N, 97º19' W, A. Salinas \& E. Martínez-Correa 7893 (MEXU); Arroyo below Cueva Blanca, 22.VII. 1966 (fl), J. Schoenwetter JSOX-67 (US). Puebla: municipio de Zapotitlán, $4.5 \mathrm{~km}$ al W de San Antonio Texcala, camino a El Encinal, $18^{\circ} 24^{\prime} 0.7^{\prime \prime} \mathrm{N}, 97^{\circ} 28^{\prime} 25.5^{\prime \prime} \mathrm{W}, 4 . \mathrm{VII} .2011$ (fl, fr inmaduro), R. Redonda-Martínez, R. Medina-Lemos, M. S. Ferrucci \& M. A. Mora-Jarvio 569 (CTES, MEXU); municipio de Zapotitlán, $10.1 \mathrm{~km}$ camino a El Encinal, $18^{\circ} 25^{\prime} 49.8^{\prime \prime} \mathrm{N}, 9^{\circ} 29^{\prime} 28.2^{\prime \prime} \mathrm{W}$, 26.X.2005 (fr), R. Rosas, O. Téllez \& M. Ayala R. 176 (MEXU); municipio de Caltepec, in the vicinity of San Luis Tultitlanapa, near Oaxaca, barranca de Tlacuilosto, VII.1907 (fl), C. A. Purpus $2616 a$ (F, GH, NY).

Serjania pygmaea se reconoce fácilmente por la combinación de los siguientes caracteres: hojas 3-folioladas con la cara abaxial pubescente, pelos blan- 

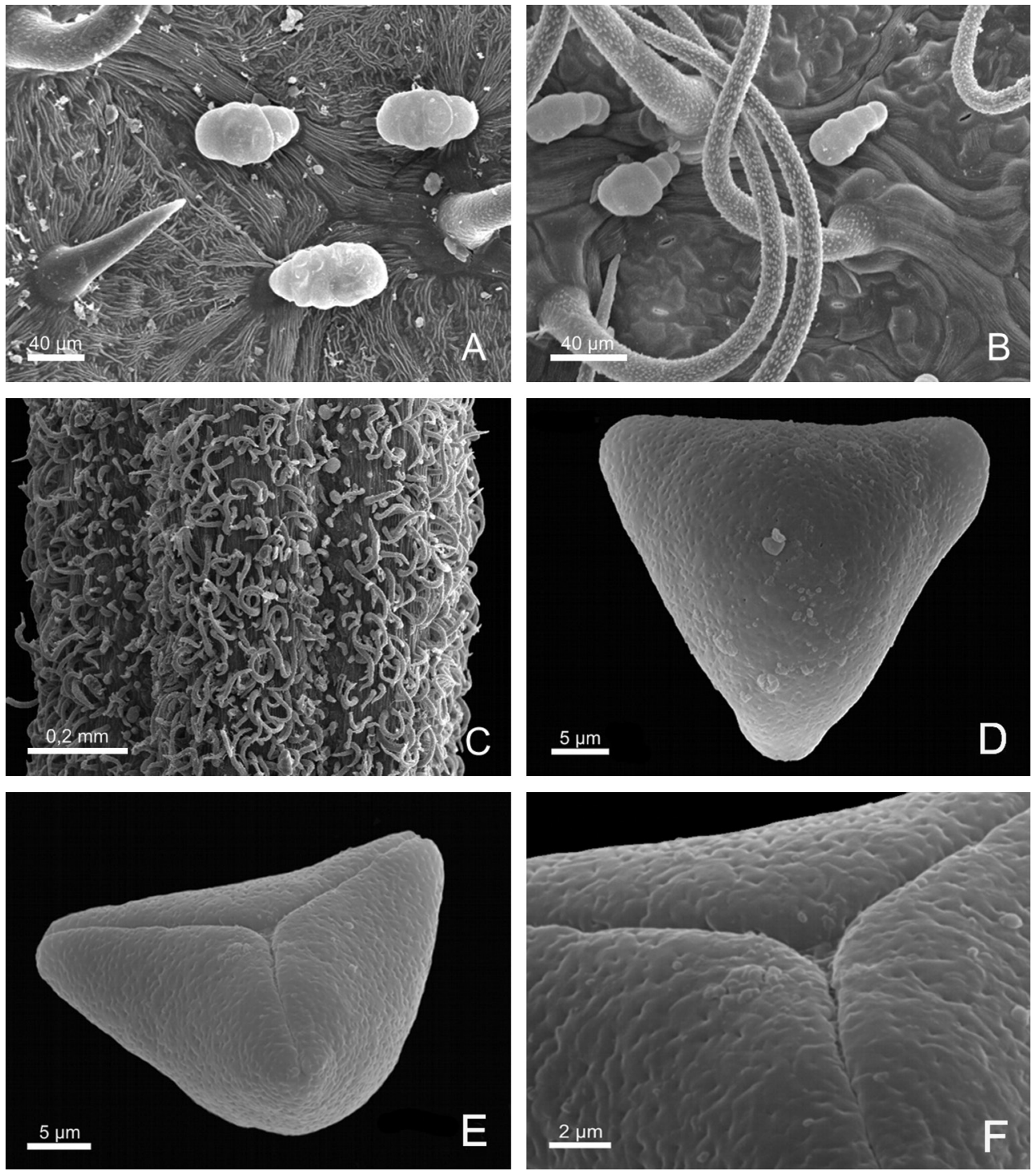

Fig. 3. Serjania pygmaea. Fotomicrografías obtenidas con microscopio electrónico de barrido. HOJA: A. detalle de la cara adaxial de la hoja mostrando la cutícula fuertemente estriada, tricomas simples y glandulares curvos; B. detalle de la cara abaxial de la hoja, se observan la cutícula lisa, estomas, tricomas simples curvos y glandulares curvos; C. detalle del tallo, se aprecian tricomas simples, crespos y glandulares curvos; POLEN: D. vista polar distal del polen; E. vista subsolar del polen; F. detalle de la apertura sincolpada del polen (A-C: Redonda-Martínez et al. 569, CTES; A. Salinas \& E. Martínez-Correa 7893, MEXU). 


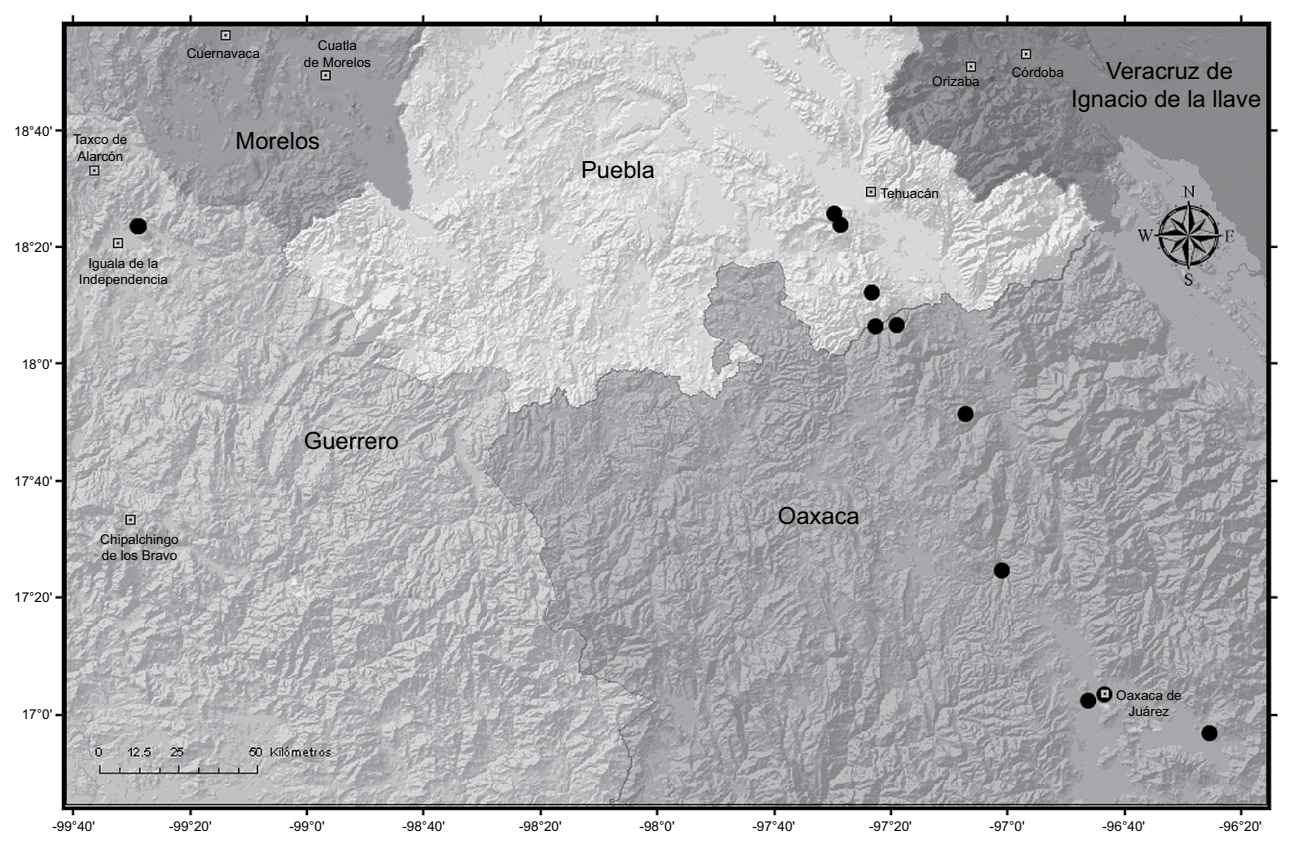

Fig. 4. Distribución geográfica de Serjania pygmaea.

quecinos curvos, subadpresos y por sus flores con 2 lobos nectaríferos posteriores ovoide-obtusos, conspicuos. Serjania pygmaea comparte los caracteres hojas 3-folioladas y tallo con cámbium único solo con tres de las especies registradas para México: $S$. grosii Schltdl., S. emarginata Kunth y $S$. trifoliolata Radlk. En el Cuadro 1 se presentan los principales caracteres que permiten distinguir estos cuatro taxones; los datos de la distribución geográfica de $S$. grosii fueron tomados de Tropicos (2012), mientras que en los otros casos se obtuvieron de los respectivos protólogos.

De acuerdo con el tratamiento del género realizado por Radlkofer (1931-1932), Serjania pygmaea correspondería a la sección Syncoccus Radlk., caracterizada por los septos del fruto tan anchos como el lóculo y totalmente fusionados. Dicha sección fue incluida por Acevedo-Rodríguez (1993) en la sección Serjania; S. pygmaea no podría ubicarse en Serjania por el pericarpo membranáceo y no leñoso como en los demás miembros de la misma.

Esta especie se conocía sólo del ejemplar tipo, procedente del cerro de Santa Lucía, Puebla. Con los nuevos registros se amplía su área de distribución conocida 
Cuadro 1. Comparación de caracteres morfológicos y de distribución de Serjania pygmaea, S. grosii, S. emarginata y S. trifoliolata

\begin{tabular}{|c|c|c|c|c|}
\hline Carácter & S. pygmaea & S. grosii & S. emarginata & S. trifoliolata \\
\hline Indumento & $\begin{array}{l}\text { presente, } \\
\text { pubescente, } \\
\text { pelos simples } \\
\text { y pelos } \\
\text { glandulares } \\
\text { curvos dispersos } \\
\text { en tallos, pecíolo } \\
\text { y ejes de la } \\
\text { inflorescencia }\end{array}$ & ausente & $\begin{array}{l}\text { ausente, a } \\
\text { excepción del } \\
\text { tirso y pecíolo }\end{array}$ & ausente \\
\hline $\begin{array}{l}\text { Forma del } \\
\text { folíolo terminal }\end{array}$ & $\begin{array}{l}\text { ovado, ovado- } \\
\text { romboidal } \\
\text { u obovado- } \\
\text { romboidal }\end{array}$ & ovado & ovado & suborbicular \\
\hline \multicolumn{5}{|l|}{ Pétalos: } \\
\hline $\begin{array}{l}\text { Longitud } \\
\text { Cara adaxial }\end{array}$ & $\begin{array}{l}4-4.3 \mathrm{~mm} \\
\text { densamente } \\
\text { glandulosa }\end{array}$ & $\begin{array}{l}\text { ca. } 1.5 \mathrm{~mm} \\
\text { eglandulosa }\end{array}$ & $\begin{array}{l}\text { ca. } 1.8 \mathrm{~mm} \\
\text { densamente } \\
\text { glandulosa }\end{array}$ & $\begin{array}{l}\text { ca. } 2.5 \mathrm{~mm} \\
\text { escasos pelos } \\
\text { glandulares }\end{array}$ \\
\hline $\begin{array}{l}\text { Lobos } \\
\text { nectaríferos }\end{array}$ & $\begin{array}{l}2 \text { posteriores } \\
\text { ovoide-obtusos, } \\
2 \text { anteriores } \\
\text { menores, } \\
\text { de contorno } \\
\text { suborbicular }\end{array}$ & $\begin{array}{l}2 \text { posteriores } \\
\text { ovoide- } \\
\text { oblongos, } \\
\text { obtuso o agudos, } \\
2 \text { anteriores } \\
\text { menores, } \\
\text { de contorno } \\
\text { elíptico-anular }\end{array}$ & $\begin{array}{l}2 \text { posteriores } \\
\text { de contorno } \\
\text { redondeado, } \\
2 \text { anteriores } \\
\text { menores, } \\
\text { de contorno } \\
\text { elíptico-anular }\end{array}$ & $\begin{array}{l}2 \text { posteriores } \\
\text { de contorno } \\
\text { elíptico, } 2 \\
\text { anteriores } \\
\text { reducidos }\end{array}$ \\
\hline Epicarpo & $\begin{array}{l}\text { piloso, pelos } \\
\text { cortos y curvos }\end{array}$ & glabro & glabro & glabro \\
\hline $\begin{array}{l}\text { Semilla: } \\
\text { Inserción en el } \\
\text { lóculo }\end{array}$ & $\begin{array}{l}\text { ligeramente } \\
\text { arriba de la base }\end{array}$ & $\begin{array}{l}\text { debajo de la } \\
\text { mitad }\end{array}$ & en la mitad & en la base \\
\hline Distribución & $\begin{array}{l}\text { México (Puebla, } \\
\text { Oaxaca y } \\
\text { Guerrero) }\end{array}$ & $\begin{array}{l}\text { México } \\
\text { (Campeche, } \\
\text { Chiapas y } \\
\text { Tabasco); } \\
\text { Belice, } \\
\text { Nicaragua, } \\
\text { Honduras y } \\
\text { Guatemala }\end{array}$ & $\begin{array}{l}\text { México } \\
\text { (Guerrero) }\end{array}$ & $\begin{array}{l}\text { México } \\
\text { (Colima) }\end{array}$ \\
\hline
\end{tabular}


a los estados de Oaxaca y Guerrero. Del material aquí citado, sólo el ejemplar $A$. Salinas \& E. Martínez-Correa 6146 (MEXU), recolectado en Oaxaca, está citado en la Flora del Valle de Tehuacán-Cuicatlán, bajo Urvillea ulmacea Kunth (CalónicoSoto, 2011).

\section{AGRADECIMIENTOS}

Agradecemos a L. Simón por preparar la excelente ilustración y a W. Medina y G. Pieszko por la digitalización de las imágenes. La primera autora agradece a su amiga y colega Rosario Redonda-Martínez y al eximio recolector Esteban Martínez-Salas por su invalorable ayuda en la recolección del material. Este trabajo fue financiado con fondos aportados por una beca de la Myndel Botanica Foundation 2011, por la Agencia Nacional de Promoción Científica, Tecnológica y de Innovación (ANPCyT-UNNE, PICTO 2011-0202) y por la Universidad Nacional del Nordeste (PI A005-2009).

\section{LITERATURA CITADA}

Acevedo-Rodríguez, P. 1993. Systematics of Serjania (Sapindaceae) part. 1: a revision of Serjania sect. Platycoccus. Mem. New York Bot. Gard. 67: 1-93.

Calónico-Soto, J. 2011. Sapindaceae. In: Medina-Lemos, R. (ed.). Flora del Valle de Tehuacán-Cuicatlán 86. Instituto de Biología, Universidad Autónoma de México, México, D.F., México. pp. 1-40.

Erdtman, G. 1966. Pollen morphology and plant taxonomy. Angiosperms. Hafner Publishing Company. New York, USA. pp. 1-553.

Ferrucci, M. S. 2000. Revisión de los géneros Cardiospermum y Urvillea para el Neotrópico (Sapindaceae). PhD Thesis. Universidad Nacional de Córdoba. Córdoba, Argentina. pp. 1-262.

Ferrucci, M. S. 2008. Sapindaceae. Catálogo de las plantas vasculares del Cono Sur. Monogr. Syst. Bot. Missouri Bot. Gard. 107: 2938-2951.

Ferrucci, M. S. y P. Acevedo-Rodríguez. 2005. Three new species of Serjania (Sapindaceae) from South America. Syst. Bot. 30: 153-162.

Ferrucci, M. S. y L. M. Anzótegui. 1993. El polen de Paullinieae (Sapindaceae). Bonplandia 6: 211-243.

Punt, W., P. P. Hoen, S. Blackmore, S. Nilsson y A. Le Thomas. 2007. Glossary of pollen and spore terminology. Rev. Palaeobot. Palynol. 143: 1-81.

Radlkofer, L. 1931-1932. Sapindaceae. In: Engler, A. (ed.). Das Planzenreich IV. 165(Heft 98a). Verlag von H. R. Engelmann (J. Cramer). Weinheim, Alemania. pp. 1-425. 
Ferrucci y Medina-Lemos: Nueva combinación para una especie de Serjania (Sapindaceae)

Somner, G. V., M. S. Ferrucci, P. Acevedo-Rodríguez \& R. Coelho G. 2010. Sapindaceae. In: Campostrini Forzza, R. \& P. Leitman (coord.). Catálogo de Plantas e Fungos do Brasil. Vol. 2. Angiospermas. Gráfica Santa Marta. Jardim Botânico do Rio de Janeiro. Rio de Janeiro, Brasil. pp. 1606-1620.

Tropicos.org. Missouri Botanical Garden. 04 Dic 2012 http://www.tropicos.org/ Name/28600413

Recibido en diciembre de 2012.

Aceptado en marzo de 2013. 